This is the peer reviewed version of the following article: Hasler, L., Ruthven, I. and Buchanan, S. (2014), Using internet groups in situations of information poverty: Topics and information needs. Journal of the American Society for Information Science and Technology, 65: 25-36, which has been published in final form at https://doi.org/10.1002/asi.22962. This article may be used for non-commercial purposes in accordance with Wiley Terms and Conditions for self-archiving.

\title{
Using Internet Groups in Situations of Information Poverty: Topics and Information Needs
}

\section{Laura Hasler*, Ian Ruthven and Steven Buchanan}

University of Strathclyde, Department of Computer and Information Sciences, Livingstone Tower, 26

Richmond Street, Glasgow G1 1XH, UK

Telephone: 0141548 \{3081, 3098, 3409\}; Fax: 01415484523

\{Laura.Hasler, Ian.Ruthven, Steven.Buchanan\}@ strath.ac.uk

* Corresponding author

\begin{abstract}
This study explores the use of online newsgroups and discussion groups by people in situations of information poverty. Through a qualitative content analysis of 200 posts from across Internet groups, we identify topics and information needs expressed by people who feel they have no other sources of support available to them. We uncover various health, wellbeing, social and identity issues which are not only crucial to the lives of the people posting, but which they are unwilling to risk revealing elsewhere - offering evidence that these online environments provide an outlet for the expression of needs in situations of critical and hidden information need. To enable this analysis, we first describe our method for reliably identifying situations of information poverty in messages posted to these groups and our coding approach. Our work contributes to the study of both information seeking within the context of information poverty and the use of Internet groups as sources of information and support, bridging the two by exploring the manifestation of information poverty in this particular online setting.
\end{abstract}

\section{INTRODUCTION}

In recent years the Internet has become a popular social resource, where people can interact with others to address various everyday life issues and seek support in times of personal crisis. There is a substantial body of literature reporting information and support behaviour in specific online communities or groups (Finn \& Lavitt, 1994; McKenna \& Bargh, 1998; Klaw, Huebsch, \& Humphreys, 2000; Lasker, Sogolow, \& Sharim, 2005; Meier, Lyons, Frydman, Forlenza, \& Rimer, 2007; Rodham, Gavin \& Miles, 2007; Eichhorn, 2008), as well as both positive and negative aspects and effects of using the Internet to find support (Kraut et al., 1998; Burrows, Nettleton, Pleace, Loader \& Muncer, 2000; Kraut et al., 2002; Bargh \& McKenna, 2004; Hu, 2007). The 
Internet can transcend geographical and social constraints, providing a source of support which may not be available elsewhere (McKenna \& Bargh, 1998; Davison, Pennebaker, \& Dickerson, 2000; Wilson \& Peterson, 2002; Hamer, 2003; Wright \& Bell, 2003). The anonymous interaction it facilitates allows people to seek information more freely, making it particularly useful for people who feel they cannot share their concerns in their usual social environments.

Chatman's theory of information poverty (Chatman, 1996) characterises situations where people are unwilling to approach others in their usual social environments for much-needed information, hiding their information needs from potential sources of help. Information poverty is determined by self-protective behaviours in response to social norms, and so these norms dictate the types of information which may and may not be sought. Often people will not risk revealing certain information needs because of the potential negative impact on their lives and as a result see themselves as devoid of information sources even though there may be support available. The theory was developed on the basis of information behaviour in physical environments, focusing on how people in economically poor communities create and maintain situations of information poverty rather than how they try to extricate themselves from it. Other studies which use Chatman's theory of information poverty as a framework also tend to focus on physical world interactions of specific communities, although not necessarily economically poor (Hamer, 2003; Sligo \& Jameson, 2000; Sligo \& Williams, 2001; Spink \& Cole, 2001; Veinot, 2009; Lingel \& boyd, in press), and where Internet use is considered as a way of combating the situation, it is seen as part of the wider process of information seeking (Hamer, 2003; Veinot, 2009; Lingel \& boyd, in press), although for some it may be the only way out. Hasler and Ruthven (2011) recently started to explore Internet groups as the sole source of support in situations of information poverty, with a shift in focus from specific communities to discussion groups in general.

Although we can conclude from the current literature that the Internet is potentially a very useful resource for those in situations of information poverty, it has yet not been adequately investigated as the primary source of help for these individuals. This study investigates the information sought by such people when using Internet groups to actively seek help from others for concerns crucial to their everyday lives. We focus on answering the question of what topics of information needs cause people to turn to the internet rather than asking for help within their immediate social environments (2). Through a qualitative content analysis of 200 selected posts from various online newsgroups and discussion groups, we provide a description of the topics expressed in 
messages posted to Internet groups when trying to alleviate or improve situations of information poverty. Our work contributes to the understanding of information seeking activities of people who feel they have no other avenues of support for critical information needs. It also explores Chatman's theory of information poverty in a new setting, contributing to the existing body of literature on this topic, as well as to online information and support seeking and support groups more generally.

\section{RELATED WORK}

Related work falls into two main strands: research dealing with the concept of information poverty and research on Internet groups or communities within which people seek and share information and support on various topics. Each strand is addressed separately below to further contextualise the present study, concentrating on the most relevant literature.

\section{Information Poverty}

The theoretical framework for our study is Chatman's theory of information poverty (Chatman, 1996), which provides an account of the information world of poor people in various communities in the US. Chatman considers the information behaviour of specialised populations through several ethnographic studies. She draws on the sociological concepts of insider/outsider and social norms to develop her theory, building on her earlier work on information in relation to economically poor groups (Chatman, 1991; 1992). Chatman investigated the information seeking and sharing behaviours of university janitors, retired women and women involved in an employment scheme, and observed that people in these groups would not reveal needs or share information that they felt would put them at some kind of disadvantage or would make them seem less able to cope than others. Examples are information around job opportunities (for employment scheme participants), financial problems (for janitors), and loneliness, health concerns and inability to cope (for retired women). These types of information and information needs were commonly hidden due to issues of fear, mistrust and irrelevance. Whilst Chatman focused mainly on economically poor groups, other researchers have used the theory to inform studies or interpret findings related to other marginalised groups such as people with HIV/AIDS (Veinot, 2009), young gay men (Hamer, 2003), members of an extreme body modification community (Lingel \& boyd, in press) and Pacific Islanders in a New Zealand health care setting (Sligo \& Jameson, 2000), as well as economically poor groups (Sligo \& Williams, 2001; Spink \& Cole, 2001). As a substantial part of the literature on Internet support groups (see below) also deals with what can be considered marginalised groups, Chatman's theory can be 
appropriately applied in these environments. Information poverty is built around four linked concepts: secrecy, deception, risk-taking and relevance. Six propositions related to these concepts are also specified in order to describe an impoverished information world (Chatman, 1996: 197-198):

1. People who are defined as information poor perceive themselves to be devoid of any sources that might help them.

2. Information poverty is partially associated with class distinction. That is, the condition of information poverty is influenced by outsiders who withhold access to privileged information.

3. Information Poverty is determined by self-protective behaviors which are used in response to social norms.

4. Both secrecy and deception are self-protecting mechanisms due to a sense of mistrust regarding the interest or ability of others to provide useful information.

5. A decision to risk exposure about our true problems is often not taken due to a perception that negative consequences outweigh benefits.

6. New knowledge will be selectively introduced into the information world of poor people. A condition that influences this process is the relevance of that information in response to everyday problems and concerns.

Other studies using information poverty as a framework for research on information behaviour have also focused on specific groups and been conducted in physical environments, only considering Internet use as one possible information seeking activity where it is mentioned at all. Spink and Cole (2001) examine information seeking and needs within low income African American households in a specific housing project, using information poverty as one of several theories to contextualise their research. They explore information needs around news, security, health, education and employment, and match these needs to different information seeking channels. Sligo and Jameson (2000) use a number of theories, including information poverty, to frame and interpret results of their study on cervical screening participation in New Zealand Pacific and non-Pacific women. Whilst the Pacific Islanders group had some information behaviours in common with Chatman's groups, other aspects such as accepting and using information from outsiders were markedly different. The findings suggest that community-specific factors, including cultural ones, affect information seeking and channels. In a later study (Sligo \& Williams, 2001), the propositions of the theory are explicitly tested by interviewing people of low socio-economic status in New Zealand, again concluding that information poverty 
differs depending on the community in which it appears. They found evidence of self-protection and the selective introduction of new knowledge, but not of the other propositions.

Veinot (2009) looks at stigma management and information poverty in relation to the use of information and help networks by people with HIV/AIDS, considering a group which is marginalised for non-economic reasons. She found that some respondents preferred to search for help from a distance or anonymously (including via the Internet), rather than asking local providers, in an attempt at self-protection. In Veinot's work there is evidence of self-protective behaviours, secrecy, deception, and an unwillingness to risk exposure of problems; however, people did not see themselves as completely devoid of sources of support. Hamer (2003) uses Chatman's six propositions to examine his findings about barriers and challenges in the information seeking behaviours of young gay men around coming out and gay identity. Using the Internet to interact with other young gay adults through chat rooms, message boards, web pages and online support groups was the most popular form of information seeking for this group, although they did engage in other activities, including visiting gay bars. Concealment due to fear is reported as strongly influencing their information seeking activities, making the Internet a popular choice due to the relative anonymity it enables. The participants were mainly looking for other people in a similar situation to talk to and connect with, and their information needs related to labeling oneself as gay, consequences of gay self-identification and gaining a fuller understanding of a gay identity. Hamer's results connect with four of the propositions, relating to a lack of resources, use of self-protective behaviours, unwillingness to risk revealing a need, and mistrust of 'outsiders' in providing useful information.

Lingel and boyd (in press) use the constructs of information poverty and stigma to examine the online and offline information practices of a subcultural community of people involved with extreme body modification, with particular emphasis on collective social norms and boundaries. Whilst information poverty acts as a means of self-protection, barriers are created not just between insiders and outsiders but also sometimes within the community itself. They found that the Internet was crucial for accessing information, allowing community members to learn about procedures, identify practitioners and locate others with the same modification. However, face to face encounters within this community are vital to its members. Similar to our approach of taking topics and information needs as the starting point in our analysis of information poverty, the authors advocate the need to consider information itself, i.e., what people seek and share, as stigmatised (cf. Hasler \& Ruthven, 2011), not just the community or person. 


\section{Online Support Groups}

Given the importance attached to the use of self-protective behaviours to conceal one's real situation of need in information poverty studies, information seeking activities may be enabled through a source which allows concealment (Hamer, 2003). The anonymity afforded by the Internet has been cited as a critical reason for its use, especially by those who may be considered marginalised or with stigmatised identities, to find support and information (McKenna \& Bargh, 1998; Davison et al., 2000; Hamer, 2003; Rodham et al., 2007; Eichhorn, 2008). Online support groups are recognised as generally supportive and friendly in nature (Finn \& Lavitt, 1994; Klaw et al., 2000; Eichhorn, 2008), making them particularly suitable for addressing problems that people feel unable to discuss in other arenas due to the pressure of social norms which can result in (perceived) negative judgement. They also enable access to a larger amount and wider variety of relevant information, advice, opinions and experiences than may otherwise be accessible (Burrows et al., 2000; Wright \& Bell, 2003; Lasker et al., 2005; Rodgers \& Chen, 2005). In addition to information, online groups are often valuable sources of emotional support (Perron, 2002; Wright \& Bell, 2003; Rodgers \& Chen, 2005; Eichhorn, 2008).

There is a vast array of newsgroups, support groups, discussion groups and forums available online, catering to a wide range of topics, interests and communities. For the purposes of this paper, we briefly describe a range of topics dealt with by online groups in the literature (see Hasler, Ruthven \& Buchanan (in preparation) for an overview of uses/functions and behaviour in relation to such groups). There is a prevalence of health- and wellbeing-related groups reported in the literature, ranging from general disability and various illnesses (Burrows et al., 2000; Davison et al., 2000) to cancer (Rodgers \& Chen, 2005; Meier et al., 2007) to rare diseases (Lasker et al., 2005) to alcoholism (Klaw et al., 2000) to mental health issues such as eating disorders (Winzelberg, 1997; Eichhorn, 2008), self-harm (Rodham et al., 2007), sexual abuse survival (Finn \& Lavitt, 1994) and caring for people with schizophrenia and related illnesses (Perron, 2002). Also studied are groups relating to social and identity issues such as parenting (Burrows et al., 2000), sexual and political/ideological identities (McKenna \& Bargh, 1998) and mortgage repossession (Burrows et al., 2000), as well as a community for older adults (Wright, 2000).

Several of these studies also present the topics discussed within the specific groups. Burrows et al. (2000) found various topics discussed in a newsgroup concerned with disability, including attitudes of society and politicians 
towards disabled people and issues related to benefits and welfare payments. Requests for and offers of information were often combined with debate and argument. In relation to a parenting group, they discovered topics such as discipline, moral and educational development, health and physical well-being, and topical debates (e.g. the MMR vaccine). Their mortgage repossession forum demonstrated the topics of 'homebuying', 'arrears', 'repossession', 'blacklisted? Who helps', and 'facts', amongst other standard web forum pages (e.g. 'welcome', 'site map'). A study of a group for individuals with eating disorders (Winzelberg, 1997) identified the following themes of information provided by members: psychological aspects of eating disorders, medical aspects of eating disorders, nutritional advice and obtaining psychological or psychiatric assistance. Perron (2002) found that discussion of emotions prevailed in a group for caregivers of people with schizophrenia. Diagnoses, symptoms, medications and treatment were also commonly found. Other topics included social networks, professionals, legal, personal, resources and finance. Lasker et al. (2005) report an emphasis on biomedical content in an online group for people with primary bilial cirrhosis (a rare disease poorly understood by the medical community), with people most often discussing health care providers, medication, tests and procedures and symptoms. In a breast cancer group, the topics of treatment and how to communicate with healthcare providers were most commonly discussed (Meier et al., 2007).

The variety of online groups available and the range of subjects covered by them, combined with the concealment enabled by the Internet, make them prime environments in which people in situations of information poverty could potentially seek much-needed information and support on topics central to their everyday lives. Topics previously examined in the context of information poverty relate to health, social and identity issues - issues also reflected in the types of online support and discussion groups reviewed above.

\section{METHODS}

We use Chatman's theory of information poverty (Chatman, 1996) as a framework to identify and analyse messages posted to newsgroups and discussion groups. Posters do not always explicitly include content which can be used to identify a situation of information poverty which means that pinpointing relevant posts is not an easy task. It was necessary to start with a set of indicators which allowed us to identify a number of potentially suitable posts, then manually check these to ensure suitability and use them to build on the indicators to account for other possible expressions of the concept. The methods we apply here for data collection and coding are similar to those described in Hasler and Ruthven (2011) and we undertake the following steps: 
1. Data collection: creation of key phrases, search of online groups, filtering of data

2. Data preparation: cleaning and anonymisation of data

3. Data analysis:

a. Broad coding for topics (top-level coding)

b. Narrower coding based on individual topics emerging from the data (grounded approach for the development of sub-codes)

\section{Data Collection and Preparation}

Google Groups (3) provides the source of data for analysis in our project, enabling access to a large number of posts from a wide range of Usenet newsgroups and other discussion groups. The interface allows searching via specified words or phrases and results can be restricted by group, time, subject and author if necessary. We searched across groups, first restricting the results to Usenet ('googlegroups') then widening this to 'all groups', as our aim was to gauge the kinds of things that people only feel comfortable asking about online rather than to investigate group-specific characteristics. Using Chatman's propositions as a basis, we formulated key search phrases which attempted to capture the basic theoretical tenets of a lack of information sources and an engagement in secrecy and/or deception as these were most obviously identifiable in a text-based analysis. These phrases were therefore based around information sources as opposed to needs or reasons for seeking information online, and included typical insider and outsider sources from 'real world' social environments inspired by previous work on information poverty (Chatman, 1996; Sligo \& Jameson, 2001; Hamer, 2003; Veinot, 2009). We initially used a small set of indicators of information poverty capturing an inability to approach specific sources of information or support, such as I cannot tell anyone; I cannot tell my parents; I cannot tell my friends; I cannot tell my doctor. We expanded these to allow variants for potential sources (family, therapist, partner, etc.), verbs of communication (ask, talk to) and modal auxiliary verbs (e.g. won't, could never, have not), as well as the more generic phrase I don't know where to turn which captured a general lack of sources. These search variants were partially guided by variation in posts already identified. Tables 1 and 2 give the complete list of search phrases used for specific sources. We identified approximately 450 potentially suitable posts which we then assessed to ensure they demonstrated a perceived lack of other sources or hidden information needs and actively sought information, and sampled for diversity of topics and expression of information needs. This method, combined with our ethics considerations (below), resulted in a set of 200 posts for further analysis. [Insert Table 1 here], [Insert Table 2 here] 
We ensured that all posts collected and analysed were taken from groups with over 100 members which were publicly searchable and accessible and which did not require registration to view content. This is to reflect an established view in the ethics literature of analysing online support communities that smaller groups may be considered to be 'private rooms' whereas larger ones are more likely to be considered 'public spaces' (Eysenbach \& Till, 2001). It is particularly relevant when dealing with groups whose members are discussing sensitive or personal topics, as may be the case in situations of information poverty. Posts were also anonymised during data preparation to protect the identity of posters and any other people or organisations mentioned. We copied relevant messages into text files, assigning each poster a numerical ID, which was kept in the message along with the date of posting, title and message content. The URLs were noted separately. Messages were anonymised by removing or replacing with meta information any potentially identifying information, such as email addresses, signatures, person names, organisation names, websites and dates of birth, for example [NAME1], [NAME2], [ORGANISATION1], [DATE]. The anonymised posts were saved as .txt files and imported into NVivo 8 for analysis.

\section{Coding for Content Analysis}

Our coding was carried out within the NVivo 8 qualitative data analysis environment, which allowed us to group together examples of content to provide evidence for our findings. The scheme and approach were developed using a sample of 25 posts from our collection to assess their suitability for larger scale application. Two authors of the paper were involved in this initial development, and the full dataset was then formally coded by one author with difficult or borderline cases being discussed and agreed on by the project team. Individual posts are taken as the unit of analysis. Within each post, we use topics and information needs as the unit of coding. Coding is not restricted to specific syntactic units or to a set number of units, but is applied to the spans of text encompassing relevant topics and needs within the posts. Different amounts of data were therefore coded in posts depending on how the information is presented; a wide variety of writing styles are represented. The narrative way in which some posts are written means that relevant information is often introduced in different places within the text, with details being added as the 'story' progresses. Other posts do not contain easily definable syntactic units such as sentences or clauses, due to lack of punctuation and use of non-standard structures. Restricting the coding span to a specified unit would mean that either irrelevant material is considered within the codes or relevant material is missed. Whilst it can make coding more difficult and time- 
consuming, using relevant text spans ultimately enables a richer analysis of the data. To ensure that we represent the data as accurately as possible in our analysis, we employed a constant comparison approach, frequently comparing coded data and code descriptions and refining the scheme as necessary. We also re-examined the data in light of any changes made to the scheme, making sure that all text spans were labeled appropriately.

In the first stage of coding, we predefined a broad top-level code informed by our research focus and Chatman's theory of information poverty. Topic-InfoNeed codes spans of text which indicate a topic that the poster is seeking information about and spans which explicitly mention any type of help that they are seeking related to that topic. No further categorisation was applied at this stage, allowing us to easily see as a whole the different kinds of concerns that the information poverty messages dealt with and the ways in which these were expressed. Some examples of text coded at this level are: (1) "I find my depression so scary - that sense of hopelessness, emptiness and desperation...I need somebody to help me... I don't have anyone or anything and I don't know how much longer I can last like this." (2) "The main thing im worried about is when we have an arguement he says that he will take my son away but he doesnt do anything for him he cant feed, change or play with him and hes always shouting and swearing at him and hes only 11 months old... ive got no where to go and no one to turn to anymore $i$ just feel so alone he makes me feel like im a bad mum when im doing the best $i$ can... i just dont know what to do i want to leave but ive no where for me and my son to go."

In the second stage of coding, we took an inductive or grounded approach (Glaser \& Strauss, 1967), examining our posts in detail and developing more fine-grained codes. These sub-codes are based on the content of the posts and range from topics such as relationships to health conditions to legal issues. Sub-codes are applied under the top-level code, enabling us to identify patterns at both general and more specific levels, for example, the first two sentences from the first Topic-InfoNeed example above would be coded first as Topic-InfoNeed (top-level), then as 'health condition' (sub-code). More than one sub-code can be applied under the top-level code as posters may mention more than one individual topic. In some posts, topics can be relatively easy to identify as they are referred to by name or by an associated term (e.g. cancer, depression indicate 'health condition'), or by prominence of language obviously associated with a topic (e.g. repetition of girlfriend in text coded as 'relationships'). In other cases, however, topics can only be established by considering the message in its entirety to gain a picture of the problem as it is built up and then interpreting the description given (this occurs, for example, with some mental health issues when a condition is not specified). The latter is also useful 
when considering the types of information and support that are sought around the topics via description and selfdisclosure, although posters do pose direct questions and requests as well.

\section{FINDINGS}

We found 21 different topics around which posters seek information, reflected by our sub-codes and summarised in Table 3 (4). Our findings build on those reported in a preliminary study (Hasler \& Ruthven, 2011). The current analysis incorporates more posts to provide a larger dataset (200 posts), leading to the development of some additional codes. As well as revealing new insights, this final description helps to validate our earlier results and the coding scheme developed during the analysis with more data. Although the primary aim of this research is to provide a qualitative analysis, the percentage of posts coded with a particular sub-code is given in parenthesis to indicate how widespread it is in the collection in comparison with others as some topics were noticeably more common than others. [Insert Table 3 here]

As described in the Methods section, our posts come from different online groups as we aimed to get a picture of information needs in the context of information poverty in these groups rather than information needs around a specific problem or community. Therefore we kept our sub-codes fairly broad as a wide range of issues could potentially be presented in the various groups that the messages were posted to. For example, we did not distinguish between different health conditions during coding as these could be many and varied, but used one broader category, 'health condition'. Some topics are much more prevalent than others, with information being sought on health conditions and relationships more often than on other topics. Others, such as homelessness and schoolwork, only occur once. Given the nature of information poverty as defined by Chatman, it is feasible that others with similar needs do not feel comfortable interacting with people even in the relatively anonymous environment of the Internet groups or that they are not even aware of this option. This said, it may just be that such subjects are not commonly asked about at all in this context. In addition to information, more emotionally oriented support is sought for many of the topics we found (cf. Klaw et al., 2000; Wright \& Bell, 2003; Rodgers \& Chen, 2005; Eichhorn, 2008), and it is not always easy to distinguish the two. Posters seek help both for their own problems and those of family and friends. Information needs are expressed by posters in several ways: making specific requests, asking specific questions, engaging in self-disclosure, describing situations or circumstances, and using combinations of these (cf. Eichhorn, 2008). For example, the following excerpt uses description to provide important contextual information and then a direct request for information on how to do 
something about this situation: "Sometimes I feel like killing myself, I get very depressed and my sister is always the last straw that almost brings me to do it. I don't know how to cope. How can I put all of this to a stop?" The individual topics that people seek information on are presented below (5).

Health conditions (51.0\%) were by far the most commonly found topic of information need, with just over half of all posts looking for help related to health, illness and injury. This category covers needs about any kind of health problem, condition, disease, disorder, worry, etc. but does not include health resources, which are considered separately below. We found a wide range of both physical and mental health issues, the majority (around three quarters) being associated with mental health. Physical health issues tended to relate to reproductive/sexual health problems or fears and cancer, although a variety of other things including epilepsy, acute noise sensitivity, skin problems and digestive problems were also present. People seeking information about mental health concerns focused primarily on depression (either diagnosed or suspected), suicidal thoughts, self-harm and eating disorders, but also anxiety, social phobia, multiple personality disorder, paranoia, stress, OCD and autism. Particularly with mental health issues, more than one condition or problem could be linked to another and posters sought help for both, for example, depression and eating disorders or depression and selfharm. Posters were interested in different aspects of health conditions depending on their personal circumstances. Their information needs centred around symptoms and diagnoses - or, less formally, explanations for situations, treatments and medication, and general information about a given condition. Posters also asked about getting better or improving a situation either with or without professional help, concealing conditions from others (especially in cases of self-harm and eating disorders), consequences of certain behaviours or actions (or a lack of them), and how to cope more generally. Examples (6):

"im also bulimic and have been for 2 years. i also feel terrified cause i feel it has me in its tight grip and feel helpless to overcome it... $i$ wonder if anyone has recovered from an ED alone? is that possible?"

"So, I am reading about Propofol, and there seems to be some reactions such as neuropathy, muscle spasm, seizures, heart attacks and so on. Therefore I am petrified even more, by the thought of this, since I already have neuropathy going on... Any thoughts on the safety or personal experiences on this drug?"

"I can't remember all the details of the type of Hep C I have- the doctor wasnt very forthcoming and I was pissed off with her attitude." 
The topic of relationships $(25.5 \%)$ addresses issues concerning relationships with parents, partners and potential partners, friends, children and other family members (usually siblings). Information needs generally relate to coping with, improving or maintaining relationships at various stages, or to starting new ones. More specifically, people seek help about break-ups and learning to get over past relationships, questions about trust, cheating, divorce, controlling parents or partners, fear of loneliness, and how to make friends, find a partner or just talk to people. Posters also ask for advice on relationships when they are affected by or involve other issues, especially health conditions (mental health), abuse, sex and pregnancy. Examples:

"I told him that I think it's best that we get a divorce he said that he came clean because it has been heavy on him and he doesn't plan on doing it again because he realized it was wrong... At this point I am hurt, and more confused than ever about what to do. What do i do now?"

"Somebody that I love deeply doesn't want me, he's avoiding me, ignoring me. I can't stop thinking about him and I don't want to live without him. What can I do? Will things ever change? Why am I suffering so? How do I move ahead in life, when I don't see the point?"

"I try so hard to make friends but nobody wants me. I try to be a good friend but I'm a horrible person and no-one wants me. :'("

Posts expressing information needs about pregnancy (8.5\%) were often linked to other topics we found, especially health, sex and relationships. However, the state of being pregnant was central to any other problems, worries or questions the poster had, and was therefore considered a topic in its own right. In a few cases, an information need about pregnancy appeared together with an information need explicitly about relationships (e.g. a relationship ending during pregnancy) or sex, but in the majority of cases pregnancy was the main issue and the posts were coded to reflect this. Posters are concerned with the health of their unborn child, getting pregnant and options such as adoption and abortion for unwanted pregnancy. Several posters are seeking verification on whether or not they are actually (likely to be) pregnant. Posts wanting information around teenage pregnancy or options for unwanted pregnancy also often convey a fear of parents' reactions. On one occasion it was a fear of a partner's reaction: a woman in a settled relationship with several other children expressed her worries that she could not cope with having another child. She did not want her partner to be upset or disappointed that she felt this way. Another post presented an alternative viewpoint on unwanted teen pregnancy, that of a teenager whose girlfriend had lied to him about birth control seeking advice on what he could and should do about the situation. These two examples really highlight situations where it is very clear 
that it is socially unacceptable to admit to having such feelings and consequently to voice concerns and seek information - prime examples illustrating information poverty. Examples:

"My girlfriend of four weeks just called. She's pregnant. She's quite happy about it... Turns out, she "forgot" to take her pills once in a while... I'm only 18... I just started college... My life is ruined."

"I am 20 years old and I just found out that I am pregnant. I don't want to be. I don't know should I abort? I just got the job, I don't love the guy who made me pregnant and I can't tell my parents about it. Please tell me what to do!!!!"

Posts concerning health resources $(6.5 \%)$ are almost always associated with specific health conditions and where needs about the two related broad topics are overtly apparent, posts are coded with both. People seek information on finding health care practitioners - mainly counselors/therapists/psychiatrists (around half of the posts) and GPs, but also dentists and cosmetic surgeons, as well as other resources such as websites or books. They are either searching for a resource for the first time, or trying to find a resource that is better than they have had access to in the past. Many of the posters seeking information on finding counselors/therapists/psychiatrists, whilst recognizing that they could benefit from seeing a health professional, feel they cannot tell their parents, friends or families that they need help and require anonymity. A few posters look for information about online support networks, including the group they post to. Examples:

"if $i$ go and see a counselor and $i$ tell that counselor that $i$ cut is the counselor allowed to tell my parents or do they have to keep my secret?"

"I've tried net searching to find a private doc who will prescribe but can't seem to. Considering trying to buy over the net which is probably a con anyway... Anyone recommend anything."

People needing information on legal issues (5.5\%) are concerned with legal rights or requirements and details of legal procedures in cases of illegal activity in various situations. In terms of legal rights and requirements, questions mostly relate to debt and divorce (particularly rights regarding costs/money and children), but also workers rights, immigration and marriage. The illegal activities covered are drug dealing and shoplifting, with posters trying to establish what could happen to the person (if) caught and likelihood of prosecution. Some posters also seek more general reassurance that everything will work out in the end. Examples:

“Advice please on employee not paying my wages for months... The company has been financially struggling since last year and they said that we had to increase sales for them to pay us any wages... I would like to have 
all my wages paid and stop the company from being able to treat employees like this in the future. Do I have any rights? And what can I do without fearing them to not pay me at all for all what is owed?"

"Are there any guidelines for long distance visitation costs-ie driving to pick them up, long distance phone bill etc."

Information and support sought around the topic of abuse (5.0\%) focuses on coming to terms with past abuse and how to deal with current abusive situations. The topic covers sexual, physical and emotional abuse, often perpetrated by relatives or friends of relatives and often sustained over a period of time. In more than half of these posts, information seeking is triggered by an event that happened in the past, in contrast with most of the other categories where the trigger event or situation is temporally much closer to the information seeking activity. Past situations relate mainly to sexual but also to physical abuse, while current situations involve emotional and physical abuse. Posters' main concerns are to do with being able to talk about the abuse and looking for general advice and support rather than asking specific questions or for specific types of help. Some posters also request help with relationships or health conditions directly related to the abuse. Many of the posts convey the feeling that the poster does not know what to do at all about the situation, or that they know what they want but do not know how to try to achieve the desired outcome, which results in a sense of helplessness or despair, for example: "i dont know how to get the pain out of my system"; "I am going crazy inside... Please, someone help me." Other examples:

"I cannot talk to my parents about my abuse at the hands of my brother. I want to bring out the anguish, see it reflected, feel it validated."

"when someone from my family abuses me i feel like there's nothing to do because $i$ have no power over them."

Information needs related to sex $(5.0 \%)$ are concerned with both physical and emotional aspects. On the physical side, people ask what happens during sex or what it will be like (where posters also want reassurance), try to establish what has happened as a result of sex, for example explanations for pain, and ask for information on health-related or legal points such as age of consent. On the emotional side, posters focus on problems experienced by their partners or by themselves, such as addiction or inability to engage in a sexual relationship. In these cases posters also tend to seek information about dealing with the relationships affected. Examples:

"Okay... This makes me nervous, but I... Well... You know the word. I do that, but today... I hit this part and it 
really hurt... It kinda hurts now. Did I do something wrong??? Can somebody tell me what i might've done????

p.s is it bad to... Do that at my age?"

"Is this normal behavior for a man that gets sex on a regular basis? Help, I don't understand!!"

People looking for support with issues of substance use (4.5\%) express information needs about dealing with addiction and advice on quitting for legal, prescription and illegal drugs, including alcohol, painkillers, sedatives and heroin. Some posters have very specific questions, such as how to use a restricted amount of drugs to ease withdrawal symptoms, whilst some simply seek advice and understanding about their situation, recognising the negative effects on their lives but being unable to stop. In several cases questions were also related to health conditions, especially mental health conditions linked to the poster's dependency. Examples:

"I'm addicted to alcohol and sedatives. The ironic part it that I never even really liked them until I used them as a coping mechanism to get off other drugs. So what now? I don't know where to turn, I don't know what to do. I just feel so hopeless. I just... I've been looking for help all over the place but I can't afford it."

"I'm still having problems staying quit after 4 years of continuous clean time. I guess that I need to talk, but this is my only safe outlet."

The topic of grief/death $(4.0 \%)$ deals with coming to terms with deaths of others, usually a loved one but sometimes of people less close to the poster, such as someone from school. There was also one case of a poster expressing her fears about her mother dying as she had recently been diagnosed with cancer. This topic is similar to the topic of abuse in that the original trigger causing the poster to seek help is not necessarily at the time of posting. In this category, posters often convey the feeling that something is wrong with them because they still cannot cope with the situation or control their feelings, in some cases after a number of years. Posters sometimes also ask for information related to mental health issues related to their feelings of grief. Examples:

"a boy in my year at school went missing on sunday and his body was found yesturday. everyone at school is upset and im not sure how to deal with it."

"we are all devistated, my mam is putting on a brave face, my younger sister is taking charge so why have i at 32 gone to pieces."

Information needs relating to bullying/harassment (3.5\%) centre around seeking information either to end a current situation (often involving blackmail) or to explain a past situation so that the poster can put it to rest and 
move on with their life. Where blackmail is involved posters tend to ask for specific information on what to do, and posters needing help with situations of bullying also ask for help with mental health issues which are very much linked to being bullied. Examples:

"The teasing is so much that it actually makes me feel bad. I am usually very able to stand up to things... Things are continuously getting worse for me... any immediate help will be greatly appreciated."

"Everytime $i$ try to he gets really really mad at me and mean and then he threatens to kill himself. But he says before he does that he is going to ruin my life and send everyone at my college naked pictures of me. I have to stay with him so i dont get humiliated. I don't know what to do."

Sexuality $(3.5 \%)$ covers issues around coming out to friends and family and dealing personally with newlydiscovered feelings or feelings that have been kept hidden for a long time. Most posters express feelings of confusion, fear or loneliness, and therefore can be considered as also seeking more general support and reassurance about their situation or identity. One poster sought advice on how to deal with their son's recent announcement that he is gay, stating that they are confused and hurt and don't know where else to turn feelings which echo those of people seeking advice related to their own sexuality. Information needs about sexuality are also sometimes associated with needs about relationships. Examples:

"I am for the moment a cross dresser. However, I am unstable, I feel like being a female at times, and others hating myself for thinking that. I love to dress but at the moment do not want to ever again."

"Recently, I've met someone who is gay. We hit it off fairly well and I do hope we could become friends. I have been thinking of telling him about myself, but I can't do it. I'm too scared. I've stayed hidden for so long the prospect of telling someone terrifies me."

The topic of money issues $(3.0 \%)$ deals with situations where posters have financial problems due to reasons such as losing a job or not being able to find work, not getting paid, getting into debt and the cost of living. Posters seek information on where to go to get financial help or to borrow money. Posts asking about debt and pay also want help with legal issues related to the posters' rights or what is legal or illegal in these circumstances. Example: "I have not been able to get a job because of the economy and I am on JSA. I have a place of our own for us to live (council) but I cannot support him on JSA... I have tried to borrow enough money to support him for a year etc but to no avail. Does anyone have any suggestions?" Information needs regarding parenting $(2.0 \%)$ relate to breast-feeding, home-schooling and discipline, seeking advice from others in similar 
situations or with experience of taking the same approach that the poster is considering. The posts are evenly split between those posing specific questions and those which describe a situation and seek more general support for a decision. Example: "I have pretty much made up my mind to hs in the fall for 1st grade, but Im so scared. its just a matter of getting my courage up and saying I can do it." People asking about religion (2.0\%) are interested in finding information on how to interpret life events such as illness or sex in the context of their religion. One poster also asks for advice on telling their religious family that they are an atheist, looking for others who are going through the same thing: "I have recently accepted myself for what I am: an Atheist... Has anyone else out there had trouble coming out as an atheist with their friends or family?"

We also found information needs relating to dreams, employment, feeling lost/lonely, alternative lifestyles, caring for others, homelessness, and schoolwork. However, posts expressing needs around these topics were very few and discussing them further would not provide many valuable insights into the broader topics themselves, but rather into individual posts.

\section{DISCUSSION}

At the most general level, we found evidence that Internet groups do provide an outlet for those suffering from information poverty to express their information needs and associated concerns. Our method of identifying posts using Chatman's concepts of secrecy and/or deception and a lack of information sources confirms that people use Internet groups as a means to try to recognise and address their needs. Whilst people may find it difficult or impossible to seek information via other channels in the 'real world', our posts indicate that Internet groups offer a place where they can at least express their needs, and hopefully obtain useful information as well as support. The analysis revealed various topics which correspond to the broader health, social and identity issues, often associated with stigma or marginalisation, previously identified in both the information poverty and online support group literature (see Related Work section).

A number of topics on which posters seek information in the groups can be can be linked to Chatman's observations that people hide information needs which might make them seem less able to cope than others or which may put them at some kind of disadvantage if revealed to those around them (Chatman, 1996). The mental health issues identified within our health condition code are particularly noteworthy as they constituted the majority $(75 \%)$ of health-related concerns, which was the largest coded category, and when separated out 
and considered in the context of the whole dataset were the largest topic of information need overall (38.5\%). Some posts seeking help with issues such as depression, suicidal thoughts, self-harm and eating disorders conveyed a sense that the poster feels they are not 'normal' or have no real reason to feel like they do because other people manage to cope with everyday life or specific life events. Also relevant are the types of information that are sought under topics such as relationships, pregnancy, abuse, grief/death, bullying/harassment, money issues, substance use and parenting. In cases of past events such as deaths or abuse, posters often feel that something is wrong with them because they cannot come to terms with what happened. Posts about parenting and pregnancy can contain what the posters thinks of as 'unnatural' feelings in the context of their lives (e.g. not wanting another child) or fears that they cannot cope with everyday situations when others can. In addition, teenage pregnancy especially can be seen as socially undesirable from the point of view of those who may be able to give information and support, such as parents. These feelings of abnormality and fear highlight the importance of social norms when seeking help: posters perceive that the topics and types of information/support they are seeking reveal needs that go against others' expectations of how things should be.

It was interesting that relationships was such a common topic in our data as these may seem a very normal thing to talk about to others. It may be precisely because relationships are such a fundamental part of everyday life that posters feel uncomfortable admitting that they need information or support, particularly in the case of longterm problems or where friends or family have been approached in the past. Several of our topics (health conditions: mental health and sexual health, sexuality, teenage pregnancy, substance use, abuse, and some legal (illegal) and money issues) still carry stigma more generally in various social contexts (cf. Lingel \& boyd (in press), for more on stigmatised information), connecting further with Chatman's role of social norms dictating what can and can't be asked as well as with related work on use of Internet interactions to seek support on issues which carry stigma (Bargh \& McKenna, 1998; Rodham et al., 2007; Eichhorn, 2008). Other information needs require specialist professional knowledge on topics, particularly legal issues, money issues and some health conditions, which may only be held by outsiders whom posters are unwilling to approach.

There are several limitations to the present study. First, due to the qualitative nature of our analysis, the findings are based on an analysis of 200 posts and are therefore not necessarily reliably generalisable. Second, we only conduct textual content analysis of messages posted to newsgroups and discussion groups. Whilst this can provide more objective data than those generated by interviews and self-reporting in terms of what was actually 
sought, it means that we cannot confirm our interpretations with the posters themselves. Third, due to our need to pinpoint posts potentially demonstrating situations of information poverty it was necessary to use an initial set of pre-defined key phrases informed by typical offline information sources. Although we expanded our initial list based on examples and semantic and grammatical variants of other sources we found in posts retrieved (see Methods section), it is conceivable that we missed some groups of sources, and as a result, other topics. Finally, a lack of demographic information in our data means that we cannot establish who expresses these types and topics of information needs in online groups.

\section{CONCLUSIONS}

We conducted a qualitative analysis which starts to explore how people suffering from information poverty in the 'real world' use Internet groups in an attempt to deal with their situation. Using key phrases based on the concepts of Chatman's original theory and related work discussing information sources, we identified indicators of information poverty to pinpoint relevant messages across various groups. Through our content analysis we gained insights into what people discuss online, establishing topics around which they seek much-needed information. Information needs relating to health, especially mental health, were particularly prevalent. Other topics reflected various health, wellbeing, identity and social issues and included relationships, pregnancy, health resources, legal issues, abuse, substance use and sexuality, among others. In line with Chatman's observations in offline settings (Chatman, 1996), many of our messages sought help on issues which posters felt would have put them at a disadvantage, or which would have made them seem less able to cope than others, had they revealed their needs in their immediate social environments. Internet groups provide an opportunity for people who feel they have no other options available to express these information and support needs.

In Hasler et al. (in preparation), we build on the study presented here by examining two other key aspects of online information seeking behaviour in the context of information poverty. Continuing our qualitative content analysis, we consider the sources from whom information needs are hidden and the reasons posters give for only being able to express information needs online (and not locally with other potential sources). This second investigation will enable a fuller picture of the use of Internet groups by people in situations of information poverty, with a focus on behaviour to give insights into how and why people use the groups, complementing our current findings regarding what is sought.

\section{FOOTNOTES}


(1) This paper builds on parts of our earlier preliminary work (Hasler \& Ruthven, 2011), offering a complete description and analysis of topics and information needs based on the full dataset of messages and evidence of information poverty in Internet groups, as well as an extended discussion of the findings.

(2) This work is part of a larger project which also considers two other central aspects of information seeking in situations of information poverty: information sources and reasons for seeking information online (see Hasler, Ruthven \& Buchanan (in preparation)).

(3) http://groups.google.com/

(4) The number of posts total more than 200 and percentages total more than $100 \%$ as it was possible to code more than one topic in each post.

(5) A number of posts mentioned potentially codeable topics which were used to frame a different concern rather than seeking information or support related to them specifically. We did not consider these contextualising topics within our analysis, only those about which help was being sought.

(6) The examples we use in the paper are excerpts from posts which demonstrate topics and information needs, rather than entire posts. Therefore, the text $\operatorname{span}(\mathrm{s})$ signalling the poster's situation of information poverty may not always be present.

\section{ACKNOWLEDGEMENTS}

This work was supported by the Economic and Social Research Council [grant number RES-000-22-4048]. We would also like to thank the anonymous reviewers for their constructive feedback which helped us to improve the paper.

\section{REFERENCES}

Bargh, J.A., \& McKenna, K.Y.A. (2004). The Internet and social life. Annual Review of Psychology, 55, 573590.

Burrows, R., Nettleton, S., Pleace, N., Loader, B., \& Muncer, S. (2000). Virtual community care? Social policy and the emergence of computer mediated social support. Information, Communication \& Society, 3(1), 95121.

Chatman, E.A. (1991). Life in a small world: Applicability of gratification theory to information-seeking behavior. Journal of the American Society of Information Science and Technology, 42(6), 438-449.

Chatman, E.A. (1992). The information world of retired women. Westport, CT.: Greenwood Press. 
Chatman, E.A. (1996). The impoverished life-world of outsiders. Journal of the American Society of Information Science and Technology, 47(3), 193-206.

Davison, K.P., Pennebaker, J.W., \& Dickerson, S.S. (2000). Who talks? The social psychology of illness support groups. American Psychologist, 55(2), 205-217.

Eichhorn, K.C. (2008). Soliciting and providing social support over the Internet: An investigation of online eating disorder support groups. Journal of Computer-Mediated Communication, 14, 67-78.

Eysenbach, G., \& Till, J.E. (2001). Ethical issues in qualitative research on Internet communities. British Medical Journal, 23, 1103-1105.

Finn, J., \& Lavitt, M. (1994). Computer-based self-help groups for sexual abuse survivors. Social Work with Groups, 17(1), 21-46.

Fourie, I. (2008). Information needs and information behaviour of patients and their family members in a cancer palliative care setting: An exploratory study of an existential context from different perspectives. Information Research, 13(4), paper 360. Retrieved from http://informationr.net/ir/13-4/paper360.html

Glaser, B.G., \& Strauss, A. (1967). The discovery of Grounded Theory. Strategies for qualitative research. Chicago, IL.: Aldine Publishing Company.

Hamer, J.S. (2003). Coming-out: Gay males’ information seeking. School Libraries Worldwide, 9(2), 73-89.

Hasler, L., \& Ruthven, I. (2011). Escaping information poverty through Internet newsgroups. In Proceedings of the Fifth AAAI International Conference on Weblogs and Social Media (ICWSM-11) (pp. 153-160). Menlo Park, CA: The AAAI Press.

Hasler, Ruthven \& Buchanan (in preparation). Using Internet Groups in Situations of Information Poverty: Information Seeking Behaviour.

Hu, M. (2007). Social use of the Internet and loneliness (Doctoral dissertation). Retrieved from $\underline{\text { http://etd.ohiolink.edu/view.cgi?acc num=osu1186168233 }}$

Klaw, E., Huebsch, P.D., \& Humphreys, K. (2000). Communication patterns in an on-line mutual help group for problem drinkers. Journal of Community Psychology, 28(5), 535-546.

Kraut, R., Kiesler, S., Boneva, B., Cummings, J., Helgeson, V., \& Crawford, A. (2002). Internet paradox revisited. Journal of Social Issues, 58(1), 49-74.

Kraut, R., Patterson, M., Lundmark, V., Kiesler, S., Mukopadhyay, T., \& Scherlis, W. (1998). Internet paradox: A social technology that reduces social involvement and psychological well-being? American Psychologist, 53(9), 1017-1032. 
Lasker, J.N., Sogolow, E.D., \& Sharim, R.R. (2005). The role of an online community for people with a rare disease: Content analysis of messages posted on a Primary Biliary Cirrhosis mailinglist. Journal of Medical Internet Research, 7(1), e10. Retrieved from http://www.jmir.org/2007/1/e10

Lingel, J., \& boyd, d. (in press). "Keep it secret, keep it safe": Information poverty, information norms, and stigma. Journal of the American Society of Information Science and Technology.

McKenna, K.Y.A., \& Bargh, J.A. (1998). Coming out in the age of the Internet: Identity "demarginalization" through virtual group participation. Journal of Personality and Social Psychology, 75(3), 681-694.

Meier, A., Lyons, E.J., Frydman, G., Forlenza, M., \& Rimer, B.K. (2007). How cancer survivors provide support on cancer-related Internet mailing lists. Journal of Medical Internet Research, 9(2), e12. Retrieved from http://www.jmir.org/2007/2/e12

Perron, B. (2002). Online Support for Caregivers of people with a mental illness. Psychiatric Rehabilitation Journal, 26(1), 70-77.

Rodgers, S., \& Chen, Q. (2005). Internet community group participation: Psychosocial benefits for women with breast cancer. Journal of Computer-Mediated Communication, 10(4), article 5. Retrieved from http://jcmc.indiana.edu/vol10/issue4/rodgers.html

Rodham, K., Gavin, J., \& Miles, M. (2007). I hear, I listen, I care: A qualitative investigation into the function of a self-harm message board. Suicide and Life-Threatening Behavior, 37(4), 422-430.

Sligo, F.X., \& Jameson, A.M. (2000). The knowledge-behavior gap in use of health information. Journal of the American Society for Information Science, 51(9), 858-869.

Spink, A., \& Cole, C. (2001). Information and poverty: Information-seeking channels used by African American low-income households. Library \& Information Science Research, 23(1), 45-65.

Sligo, F., \& Williams, J. (2001, July). Investigating information poverty and its implications for community development. Paper presented at Competing Visions - National Social Policy Conference 2001, Sydney, Australia. Abstract retrieved from http://www.sprc.unsw.edu.au/media/File/NSPC Program01.pdf

Veinot, T. (2009). "A lot of people didn't have a chance to support us because we never told them" Stigma management, information poverty and HIV/AIDS information/help networks. In A. Grove (Ed.), Proceedings of the $72^{\text {nd }}$ ASIS\&T Annual Meeting, vol. 46 (ASIST 2009). Silver Spring, MD: American Society for Information Science and Technology. Retrieved from http://www.asis.org/Conferences/AM09/open-proceedings/papers/73.xml 
Wilson, S.M., \& Peterson, L.C. (2002). The anthropology of online communities. Annual Review of Anthropology, 31, 449-467.

Winzelberg, A. (1997). The analysis of an electronic support group for individuals with eating disorders. Computers in Human Behavior, 13(3), 393-407.

Wright, K. (2000). The communication of social support within an on-line community for older adults: A qualitative analysis of the SeniorNet community. Qualitative Research Reports in Communication, 1(2), 3343.

Wright, K., \& Bell, S. (2003). Health-related support groups on the Internet: Linking empirical findings to social support and computer-mediated communication theory. Journal of Health Psychology, 8(1), 39-54. 